\title{
Acute cerebellar ataxia: differential diagnosis and clinical approach
}

\author{
Ataxia cerebelar aguda: diagnóstico diferencial e abordagem clínica \\ José Luiz Pedroso*1, Thiago Cardoso Vale*2, Pedro Braga-Neto ${ }^{3,4}$, Livia Almeida Dutra ${ }^{1,5}$, Marcondes \\ Cavalcante França Jr ${ }^{6}$, Hélio A. G. Teive7, Orlando G. P. Barsottini
}

\begin{abstract}
Cerebellar ataxia is a common finding in neurological practice and has a wide variety of causes, ranging from the chronic and slowlyprogressive cerebellar degenerations to the acute cerebellar lesions due to infarction, edema and hemorrhage, configuring a true neurological emergency. Acute cerebellar ataxia is a syndrome that occurs in less than 72 hours, in previously healthy subjects. Acute ataxia usually results in hospitalization and extensive laboratory investigation. Clinicians are often faced with decisions on the extent and timing of the initial screening tests, particularly to detect treatable causes. The main group of diseases that may cause acute ataxias discussed in this article are: stroke, infectious, toxic, immune-mediated, paraneoplastic, vitamin deficiency, structural lesions and metabolic diseases. This review focuses on the etiologic and diagnostic considerations for acute ataxia.
\end{abstract}

Keywords: Cerebellar ataxia; cerebellum; cerebellar diseases.

\section{RESUMO}

A ataxia cerebelar é um achado comum na prática neurológica e tem uma grande variedade de causas, desde a degeneração cerebelar crônica e lentamente progressiva à lesão cerebelar aguda devido a infarto, edema ou hemorragia, configurando uma verdadeira emergência neurológica. Ataxia cerebelar aguda é uma síndrome que ocorre em menos de 72 horas em indivíduos previamente saudáveis. A ataxia aguda geralmente resulta em hospitalização e extensa investigação laboratorial. Os clínicos são frequentemente confrontados com a decisão sobre a extensão e o momento dos testes de rastreio iniciais, em particular para detectar as causas tratáveis. 0 principal grupo de doenças que podem causar ataxias agudas discutidas neste artigo são: acidente vascular cerebral, infecciosas, tóxicas, imunomediadas, paraneoplásicas, deficiência de vitaminas, lesões estruturais e doenças metabólicas. Esta revisão enfoca a etiologia e considerações diagnósticas para a ataxia aguda.

Palavras-chave: Ataxia cerebelar; cerebelo; doenças cerebelares.

Cerebellar ataxia is a term that comprises a wide spectrum of neurological disorders with ataxia as the main symptom, and clinically denotes loss of balance and coordination. Furthermore, ataxia may be caused by disturbances in several parts of the nervous system (e.g., cerebellum, brainstem, spinal cord, and peripheral nerves) ${ }^{1}$.

Cerebellar ataxia is a common finding in neurological practice and has a wide variety of causes. Ataxias can

\footnotetext{
${ }^{1}$ Universidade Federal de São Paulo, Departamento de Neurologia e Neurocirurgia, Unidade de Neurologia Geral e de Ataxias, São Paulo SP, Brasil;

${ }^{2}$ Universidade Federal de Juiz de Fora, Departamento de Clínica Médica, Serviço de Neurologia do Hospital Universitário, Juiz de Fora MG, Brasil;

${ }^{3}$ Universidade Federal do Ceará, Departamento de Medicina Clínica, Divisão de Neurologia, Fortaleza CE, Brasil;

«Universidade Estadual do Ceará, Centro de Ciências da Saúde, Fortaleza CE, Brasil;

${ }^{5}$ Faculdade Israelita de Ciências da Saúde Albert Einstein, Hospital Israelita Albert Einstein, São Paulo SP, Brasil;

שUniversidade Estadual de Campinas, Departamento de Neurologia, Campinas SP, Brasil;

`Universidade Federal do Paraná, Hospital de Clínicas, Departamento de Medicina Interna, Serviço de Neurologia, Setor de Distúrbios do Movimento, Curitiba PR, Brasil.

Hélio Teive (iD https://orcid.org/0000-0003-2305-1073; Orlando Barsottini iD https://orcid.org/0000-0002-0107-0831; Pedro Braga-Neto

https://orcid.org/0000-0001-9186-9243; Livia Dutra (iD) https://orcid.org/0000-0001-6309-9077; Marcondes iD https://orcid.org/0000-0003-0898-2419;

José Luiz Pedroso (iD https://orcid.org/0000-0002-1672-8894; Thiago Cardoso Vale iD https://orcid.org/0000-0001-6145-9868

*These authors contributed equally to this work.
}

Correspondence: Orlando Barsottini; Departamento de Neurologia e Neurocirurgia, Unidade de Neurologia Geral e de Ataxias da UNIFESP; São Paulo, SP, Brasil. E-mail: orlandobarsottini@gmail.com

Conflict of interest: There is no conflict of interest to declare.

Received 18 September 2018; Received in final form 23 November 2018; Accepted 02 December 2018. 
be subdivided into six major groups: autosomal dominant spinocerebellar ataxias, autosomal recessive ataxias, congenital ataxias, mitochondrial ataxias, X-linked cerebellar ataxias and sporadic or acquired ataxias ${ }^{1,2}$. Acute cerebellar syndromes are usually acquired, non-genetic and often a neurological emergency. There is little medical literature on acute cerebellar syndromes, mainly due to their heterogeneity. Although the exact incidence is unknown, acute ataxia usually results in hospitalization and extensive laboratory investigation. Clinicians are often faced with deciding the extent and timing of initial screening tests in order to detect treatable causes ${ }^{3}$.
Acute cerebellar ataxias (ACA) are more common in childhood, often presenting as a post-infectious disorder ${ }^{4}$. The main group of diseases that may cause ACA discussed in this article are listed in Table 1 and include: stroke, infectious, toxic, immune-mediated, paraneoplastic, vitamin deficiency, structural and metabolic diseases ${ }^{3}$.

As a methodology for this review, we performed a search for the following terms in the PubMed library: "acute ataxias", "acute cerebellar syndrome", "adult sporadic ataxias", "toxic ataxias", "immune-mediated ataxias", "acquired ataxias", "cerebellitis" and "infection of the cerebellum". The most relevant reviews, original articles and case reports were used

Table 1. The main group of diseases that may cause acute cerebellar ataxias.

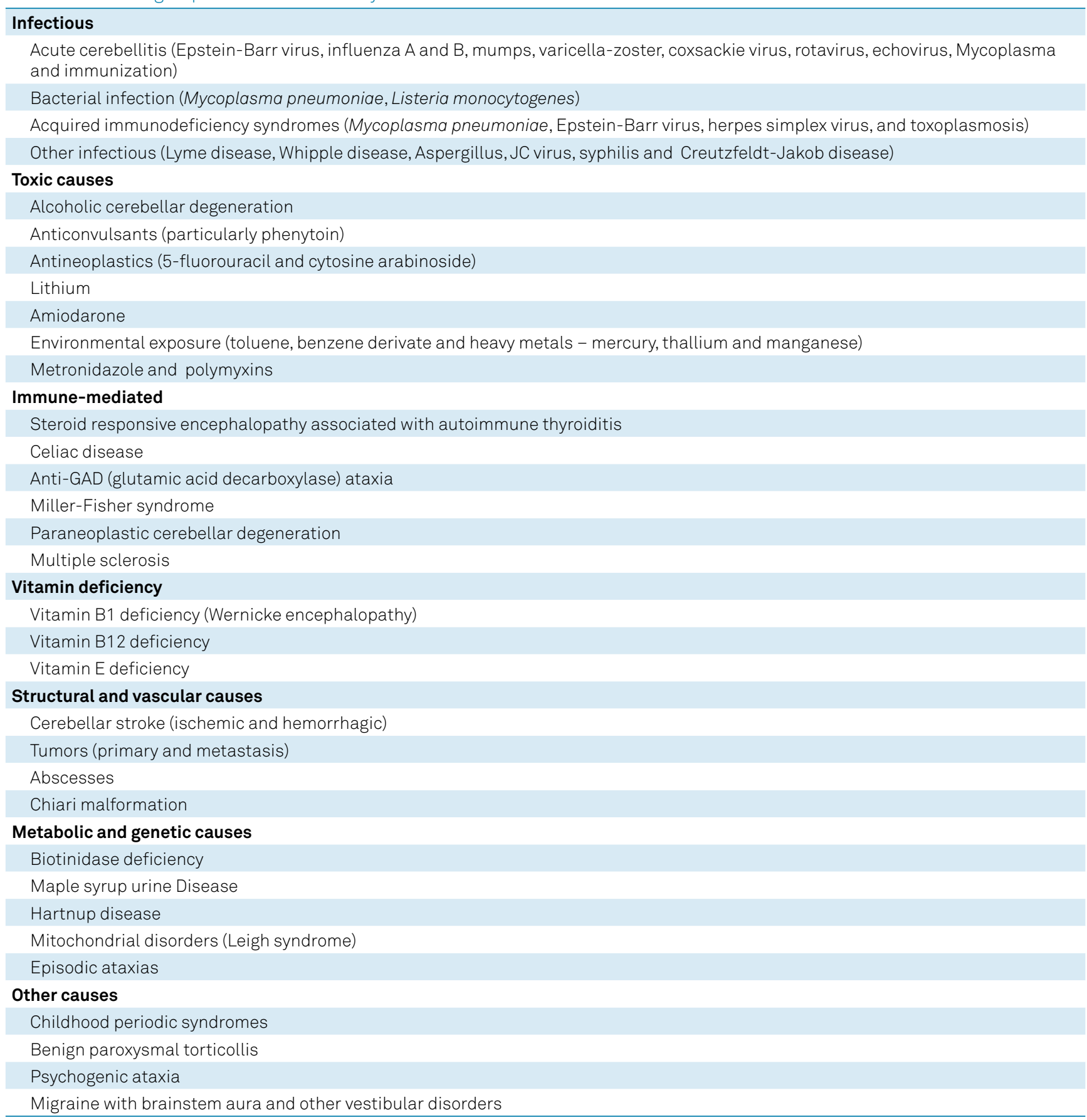


as references for this paper. On the whole, this review serves as a diagnostic approach for the clinical neurologist, and focuses on the etiology of acute ataxias.

\section{INFECTIOUS ACUTE CEREBELLAR ATAXIAS}

Acute cerebellar ataxias secondary to infectious diseases most commonly involve the posterior fossa. In the pediatric population, the most frequent cause of acute ataxia is cerebellitis ${ }^{3}$. Infectious pathogens that frequently or preferentially affect the cerebellum include Listeria monocytogenes, varicella-zoster virus, John Cunningham (JC) virus, and Creutzfeldt-Jakob disease ${ }^{5}$.

\section{Acute cerebellitis}

Acute cerebellitis represents an inflammatory disorder that results from para-infectious, post-infectious, or postvaccination cerebellar immune-mediated inflammation. Evidence of direct central nervous system infection is rarely found ${ }^{6}$. Acute post-infectious cerebellitis is more common in children and young adults. It is a pure cerebellar syndrome with normal or abnormal brain magnetic resonance imaging (MRI) at onset. Previously reported infections include: Epstein-Barr virus, influenza A and B, mumps, varicella-zoster virus, coxsackie virus, rotavirus, echovirus, Mycoplasma pneumoniae and immunization. In a large series of 73 patients with acute cerebellar ataxia, 19 had a previous varicella infection, two had Epstein-Barr virus infection, and 36 had other, presumed but unproven, viral illnesses. Fourteen cases were termed idiopathic and two were thought to be related to a vaccine. Overall, $91 \%$ recovered completely, including all children with varicella ${ }^{7}$. Other infections that may be related to ACA include hepatitis A, human herpesvirus 7, mumps and human parvovirus B193. Severe cases of acute cerebellitis may present with clinical manifestations related to increased intracranial pressure resulting from cerebellar swelling and acute hydrocephalus, which overshadow manifestations of cerebellar dysfunction and may need urgent neurosurgical decompression ${ }^{3}$.

\section{Bacterial infection}

Any bacterial infection that causes meningoencephalitis can result in cerebellar signs and symptoms, including ACA. Mycoplasma pneumoniae has also been associated with a cerebellar syndrome during, or just after, the acute illness. Considering rhombencephalitis, Listeria monocytogenes is the most common causative agent ${ }^{2}$.

\section{Acute ataxia in acquired immunodeficiency syndromes}

In patients with acquired immunodeficiency syndromes, ACA may be related to M. pneumoniae, Epstein-Barr virus, herpes simplex virus, and toxoplasmosis.

\section{Other infectious agents causing acute ataxia}

Patients with Lyme disease, Whipple disease, and Creutzfeldt-Jakob disease may also develop ataxia, and this may be the initial manifestation ${ }^{3}$. Fungi, in particular the Aspergillus species, can also cause ACA due to its tendency to cause posterior fossa invasive parenchymal disease ${ }^{5}$. Meningovascular syphilitic infection has also been reported to cause ACA in the setting of a bilateral inferior cerebellar infarction ${ }^{3}$. Subacute ataxia and abnormalities in brain MRI (Figure 1) may be caused by JC virus infection.

\section{ACUTE CEREBELLAR ATAXIA RELATED TO TOXIC CAUSES}

\section{Alcoholic cerebellar degeneration}

The cerebellum, particularly the Purkinje cells, are susceptible to a large number of toxic agents, alcohol being the most common. Alcohol may cause toxic effects on the central and peripheral nervous systems. Alcoholic cerebellar degeneration is related either to a direct toxic alcoholic effect on the Purkinje cells and vitamin B1 deficiency (see section of vitamin deficiency) ${ }^{8}$. Ataxia usually has a rapid progression (weeks or months), but slower progression may occur. Neurological features usually include severe ataxia of gait and lower limbs with relatively mild involvement of the upper limbs. Interestingly, speech and ocular motility are usually preserved. Brain imaging in alcoholic cerebellar degeneration typically shows vermis atrophy. Alcoholic cerebellar degeneration can often be accompanied by, and exacerbate, coexisting peripheral neuropathy and degeneration of posterior columns. Treatment of alcoholic cerebellar degeneration consists of abstinence from alcohol and vitamin $\mathrm{B} 1$ supplementation ${ }^{2,8}$.

\section{Antibiotic-induced acute ataxia}

Weeks after initiation of metronidazole, an encephalopathy accompanied by cerebellar signs and brain MRI abnormalities may occur. It is characterized by cerebellar dysfunction, rare seizures, and non-specific EEG abnormalities. Metronidazole toxicity results in characteristic reversible MRI signal abnormalities in the cerebellar dentate nuclei, dorsal brainstem, or splenium of the corpus callosum. Both increased and decreased diffusivity have been observed in MRI, suggesting the variable presence of both vasogenic and cytotoxic edema, respectively?

The interaction of polymyxins with neurons, which have a high lipid content, has been associated with the occurrence of several neurotoxic events. The most common is paresthesia, but ataxia may also occur in isolation or combined with dizziness, generalized muscle weakness, partial deafness, visual disturbances, vertigo, confusion, hallucinations, seizures, and neuromuscular blockade ${ }^{10}$. 

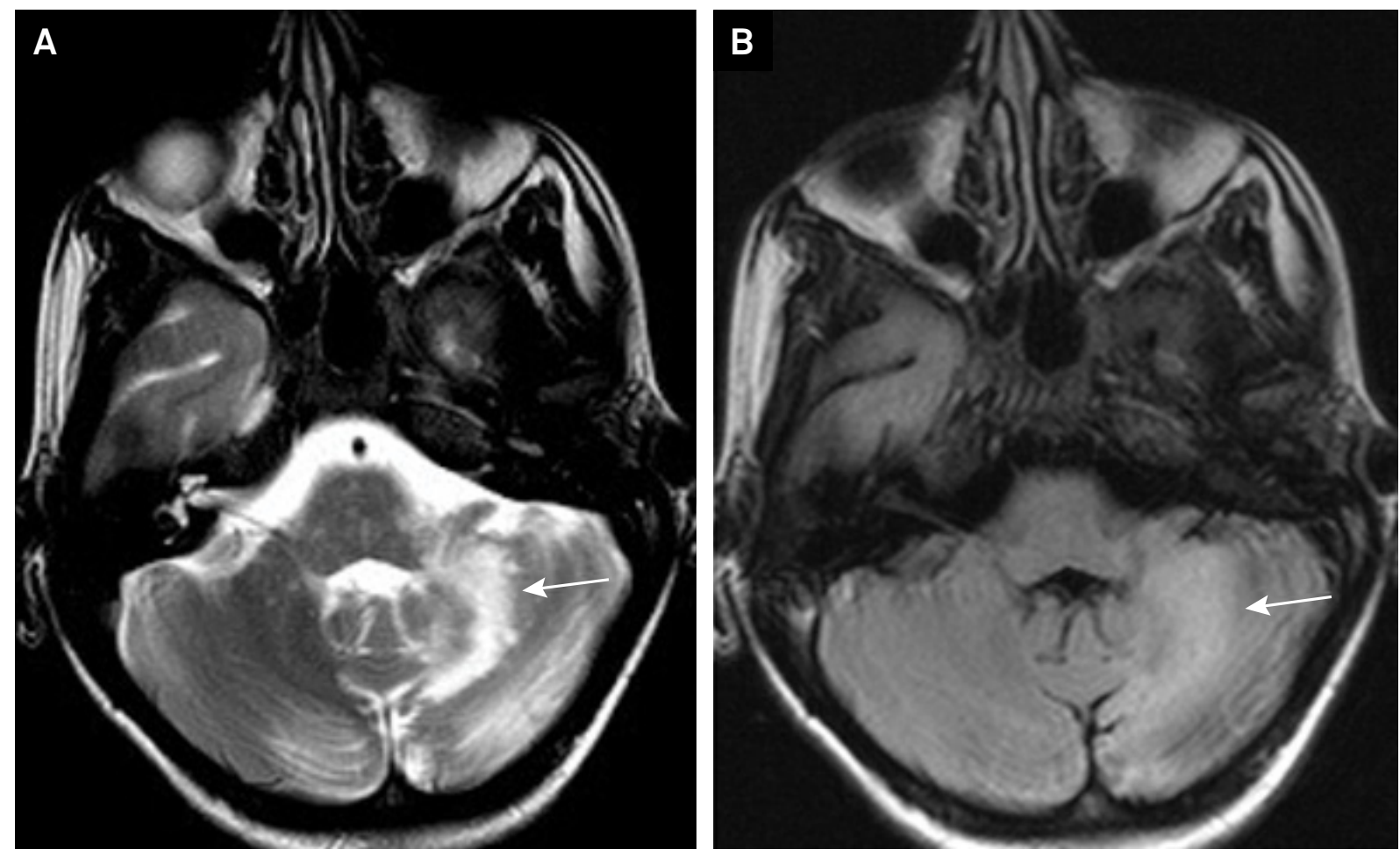

Figure 1. Patient with HIV and subacute cerebellar ataxia. Cerebrospinal fluid PCR confirmed John Cunningham virus infection (cerebellar form of progressive multifocal leukoencephalopathy). (A) Axial T2-weighted and (B) axial FLAIR-weighted brain MRI shows asymmetric hyperintense signal in the cerebellum evolving to the left cerebellar hemisphere and middle cerebellar peduncle.

\section{Other toxic agents causing acute ataxia}

Several drugs may cause toxic ataxia, dependent on the dosing and timing of use. The main agents include anticonvulsants (carbamazepine, phenobarbital, vigabatrin, gabapentin, lamotrigine and phenytoin), antineoplastics (5-fluorouracil, cytosine arabinoside, capecitabine, methotrexate), lithium and amiodarone. It is important to mention that interaction between medications can increase the plasmatic level of these agents ${ }^{2,8}$. Chemical toxins related to environmental exposure may also cause acute ataxia and include: carbon dioxide, scorpion sting, insecticides/herbicides (organophosphate), toluene, benzene derivate and heavy metals (mercury, thallium, manganese, lead and copper ${ }^{2,11}$. Drug abuse such as cocaine, heroin, methadone and phencyclidine are also important causes of toxic ataxias ${ }^{11}$.

\section{IMMUNE-MEDIATED CAUSES OF ACUTE CEREBELLAR ATAXIA}

Immune-mediated ataxias may cause acute, subacute or chronic ataxia. In this topic, we will focus on the acute and subacute autoimmune ataxias not related to a demyelinating disease, such as multiple sclerosis.

\section{Steroid responsive encephalopathy associated with autoimmune thyroiditis}

Steroid responsive encephalopathy associated with autoimmune thyroiditis is an autoimmune disorder characterized by behavioral abnormalities, seizures, ataxia, myoclonus, stroke-like episodes and high serum levels of thyroid antibodies $^{12}$. Steroid responsive encephalopathy associated with autoimmune thyroiditis hardly ever presents with a pure ataxia syndrome and is usually associated with a more complex phenotype with encephalopathy. Brain MRI may show focal or diffuse abnormalities in $50 \%$ of patients. These patients are managed with steroids and refractory cases may be treated with immunosuppressive medications ${ }^{13}$.

\section{Celiac disease or gluten ataxia}

Celiac disease is chronic immune-mediated enteropathy precipitated by gluten exposure in patients carrying HLADQ2 and/or DQ8 alleles ${ }^{14}$. Patients may develop antibodies against transglutaminase and endomysium. Cerebellar ataxia is the most common neurological manifestation, but other symptoms may occur, such as neuropathy, brain calcifications, seizures, myelopathy and dementia. Nonetheless, a recent study reported that an alternative diagnosis for neurological manifestation was found in $57 \%$ of patients with suspected celiac disease ${ }^{15}$. However, this condition is hardly ever observed in our Brazilian population (personal observation of the authors).

\section{Anti-GAD ataxia}

Glutamic acid decarboxylase antibody (GAD-Ab) neurological syndromes comprise cerebellar ataxia, limbic encephalitis, stiff-person syndrome and autoimmune epilepsy ${ }^{16,17}$. 
The clinical spectrum of ataxia associated with anti-GAD-Ab comprises subacute or chronic cerebellar ataxia syndrome evolving over months or years, associated with cerebellar atrophy on brain MRI. Cerebrospinal fluid analysis frequently depicts oligoclonal bands. Treatment with immunoglobulin might be considered in these cases. In some patients, particularly those with diseases that are associated with GAD autoimmunity (e.g., type 1 diabetes mellitus), the development of ataxia should lead to GAD65-Ab testing ${ }^{18}$.

\section{Autoimmune encephalitis}

Acute and subacute ataxia is a frequent symptom in patients with autoimmune encephalitis. Metabotropic glutamate receptor 1 (mGluR1) is a G-protein-coupled receptor, involved in long-term depression of parallel fiber-Purkinje cell synapses. Patients with anti-mGluRl encephalitis typically present with cerebellar ataxia, and almost half of the patients may present with dysgeusia ${ }^{19,20}$. Patients with anti-CAPSR-2 encephalitis may present with ataxia, limbic encephalitis and/or peripheral nerve hyperexcitability. Anti-GABA(B) encephalitis may present as acute ataxia coupled or not with limbic encephalitis and seizures. Other antibodies associated with ataxia include anti-GABA(A), anti-dipeptidyl-peptidase-like protein-6 and antibodies against IgLON family member 5 protein ${ }^{21}$.

\section{Miller-Fisher syndrome}

Miller-Fisher syndrome is a variant of Guillain-Barré syndrome, characterized by acute ataxia, areflexia and ophthalmoplegia, usually with a preceding infection. Cerebrospinal fluid shows protein cytological dissociation, brain MRI is normal and the anti-GQ1b antibody may be positive. Current evidence suggests that a dorsal root antibody attack may explain the cerebellar ataxia ${ }^{22}$.

\section{Paraneoplastic cerebellar degeneration causing acute cerebellar ataxia}

Paraneoplastic cerebellar degeneration (PCD) has an association with tumors of the ovary and breast, small cell lung cancer and Hodgkin's lymphoma, but has also been reported in association with many other types of tumors. Paraneoplastic cerebellar degeneration is seen in about $20 \%$ of paraneoplastic neurological syndromes and typically affects more females than males. The disease usually has an acute or subacute onset, with vertigo, dizziness, vomiting, and nausea, and evolves rapidly, over weeks to months, to gait ataxia, truncal and limb ataxia, dysarthria and nystagmus. Also, PCD usually reaches its peak and then stabilizes. Other signs and symptoms may be present, including dysphagia, brisk reflexes, hearing loss, extrapyramidal signs, peripheral neuropathy and cognitive impairment ${ }^{22-24}$. In patients with rapid onset ataxia (acute or subacute), clinicians should suspect a paraneoplastic disorder. Ataxia symptoms may be part of opsoclonus-myoclonus syndrome. In this syndrome, opsoclonus is associated with truncal ataxia, diffuse or focal myoclonus, vertigo, dysarthria and encephalopathy. In children, it may be associated with neuroblastoma or ganglioneuroma, and in adults with lung cancer or ovarian teratoma. The disorder is paraneoplastic in about $30-40 \%$ of children ${ }^{25}$. Onconeural antibodies are generated against tumor antigens and are cross-reactive with cerebellar tissue antigens, especially those expressed by Purkinje cells. Pathology includes loss and degeneration of Purkinje cells and other cerebellar structures. Brain MRI is usually normal, particularly in the early course of the disease (Figure 2). Later, during the disease progression, diffuse cerebellar atrophy may occur. Cerebrospinal fluid usually contains a lymphocytic pleocytosis. Paraneoplastic cerebellar degeneration has been reported with most onconeural antibodies (Table 2) ${ }^{26}$. Paraneoplastic cerebellar degeneration, without classical onconeural antibodies (seronegative PCD), is thought to represent up to $50 \%$ of patients with PCD and the clinical characteristics of seronegative and seropositive PCD are similar but the spectrum of associated tumors is different ${ }^{27}$.

Treatment is commonly unsuccessful, although an improvement or stabilization of neurological symptoms after surgical resection of the tumor may occur. Other treatment options are immunosuppressive therapies with corticosteroids, intravenous immunoglobulin, cyclophosphamide, tacrolimus, mycophenolate and, more recently, rituximab $(\text { anti-CD20) })^{28}$.

\section{Vitamin deficiency causing acute cerebellar ataxia}

Vitamin B1 (thiamine) and B12 deficiencies may cause ACA or subacute ataxia. Thiamine deficiency may cause Wernicke encephalopathy (ataxia, confusion and ophthalmoparesis), a condition usually observed in alcoholics. Besides, thiamine deficiency is also involved in the pathophysiology of alcoholic cerebellar degeneration ${ }^{29}$. Vitamin B12 deficiency causes sensory ataxia and patients present with impaired proprioception, peripheral neuropathy and pyramidal signs. Serum levels of B12 are usually decreased, and high levels of serum homocysteine and methylmalonic acid are also useful to suggest the diagnosis. The MRI may disclose a hyperintense signal in the posterior column of the cervical or thoracic spinal cord (Figure 3$)^{30}$. Symptomatic treatment comprises intramuscular B12 replacement. Vitamin E deficiency is usually related to a genetic cause and has a chronic course similar to Friedreich's ataxia ${ }^{31}$.

\section{Vascular causes of acute cerebellar ataxia}

Cerebellar stroke accounts for approximately $2 \%$ to $3 \%$ of all strokes. Acute cerebellar stroke may manifest with ataxia, vertigo, dysarthria, nausea, vomiting and, often, a prominent headache. Cerebellar infarction or hemorrhage may initially manifest in a clinically indolent manner only later to deteriorate into a life-threatening neurologic catastrophe, leading to a comatose state. These complications are mostly due 


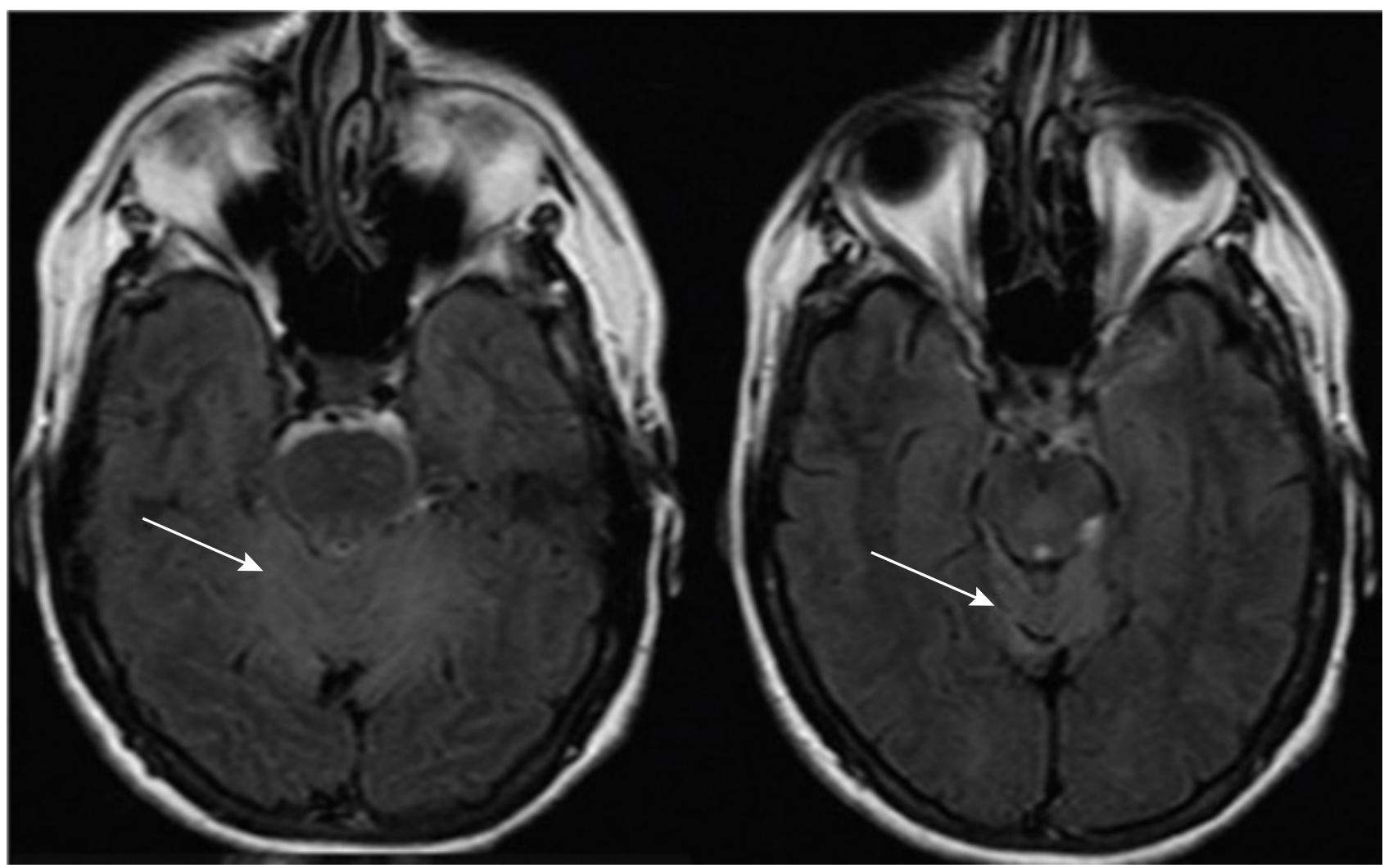

Figure 2. Patient with acute ataxia and breast cancer. Paraneoplastic cerebellar degeneration was diagnosed. Axial FLAIR-weighted brain MRI disclosed marked hyperintense signal in the superior vermis.

Table 2. Paraneoplastic cerebellar degeneration: autoantibodies, related tumors and clinical syndromes.

\begin{tabular}{|c|c|}
\hline Antibody & Related cancer \\
\hline Anti-Yo & Breast, gynecological tumors \\
\hline Anti-Hu & Small cell lung cancer \\
\hline Anti-Tr ${ }^{1}$ & Hodgkin's lymphoma \\
\hline Anti-CV2² & Small cell lung cancer, thymoma \\
\hline Anti-Ri & $\begin{array}{c}\text { Breast, ovaries, small cell lung cancer, } \\
\text { neuroblastoma }\end{array}$ \\
\hline Anti-Ma2 & Testicles, lung cancer \\
\hline Anti-VGCC & Small cell lung cancer \\
\hline Anti-SOX1 & Small cell lung cancer \\
\hline Anti-ZIC4 & Small cell lung cancer \\
\hline
\end{tabular}

${ }^{1}$ Anti-Tr is also known as anti-DNER (delta/notch-like epidermal growth factor-related receptor); ${ }^{2}$ anti-CV2 is also known as CRMP-5 (collapsin response mediator protein 5); Other antibodies: PCA-2 (the antigen was characterized as being the microtubule-associated protein [MAP1B]), anti-Homer 3, anti-CARP VIII, anti-GAD65, antibodies targeting septin-5 and GluD2 receptor antibody.

to hydrocephalus, brainstem compression by mass effect, or irreversible brainstem infarction (Figure 4) ${ }^{32}$. Approximately $20 \%$ of the patients with cerebellar stroke develop signs of clinical and radiographic deterioration due to mass effect. Cerebellar ischemia commonly occurs because of embolism, large vessel atherosclerosis or vertebrobasilar dissection in one of its three major vascular beds: posterior inferior cerebellar artery, anterior inferior cerebellar artery and superior cerebellar artery ${ }^{33}$. Ischemia of the cerebellum may coexist with ischemia of the brainstem due to pathologic abnormality in the vertebrobasilar vasculature. Thus, cranial nerve abnormalities may coexist with acute ataxia. Cerebellar hemorrhage accounts for approximately $9 \%$ to $10 \%$ of all intracranial hemorrhages. Hypertension and small vessel disease are considered the most common causes. It is frequently seen in middle-aged to older patients (usually beyond the fifth decade). The clinical spectrum of cerebellar hemorrhage is determined by its size and perilesional edema $^{34}$. Patients with small cerebellar strokes can present with classic cerebellar symptoms and those with larger strokes may become comatose and may develop other brainstem features and hydrocephalus.

\section{STRUCTURAL LESIONS CAUSING ACUTE CEREBELLAR ATAXIA}

Primary brain tumors, such as meningiomas and gliomas, as well as metastatic tumors secondary to melanoma, breast and lung cancer, may present with acute ataxia (Figure 5) ${ }^{3}$. Likewise, other pediatric posterior fossa brain tumors, including cerebellar astrocytoma and medulloblastoma, may present with ACA and 


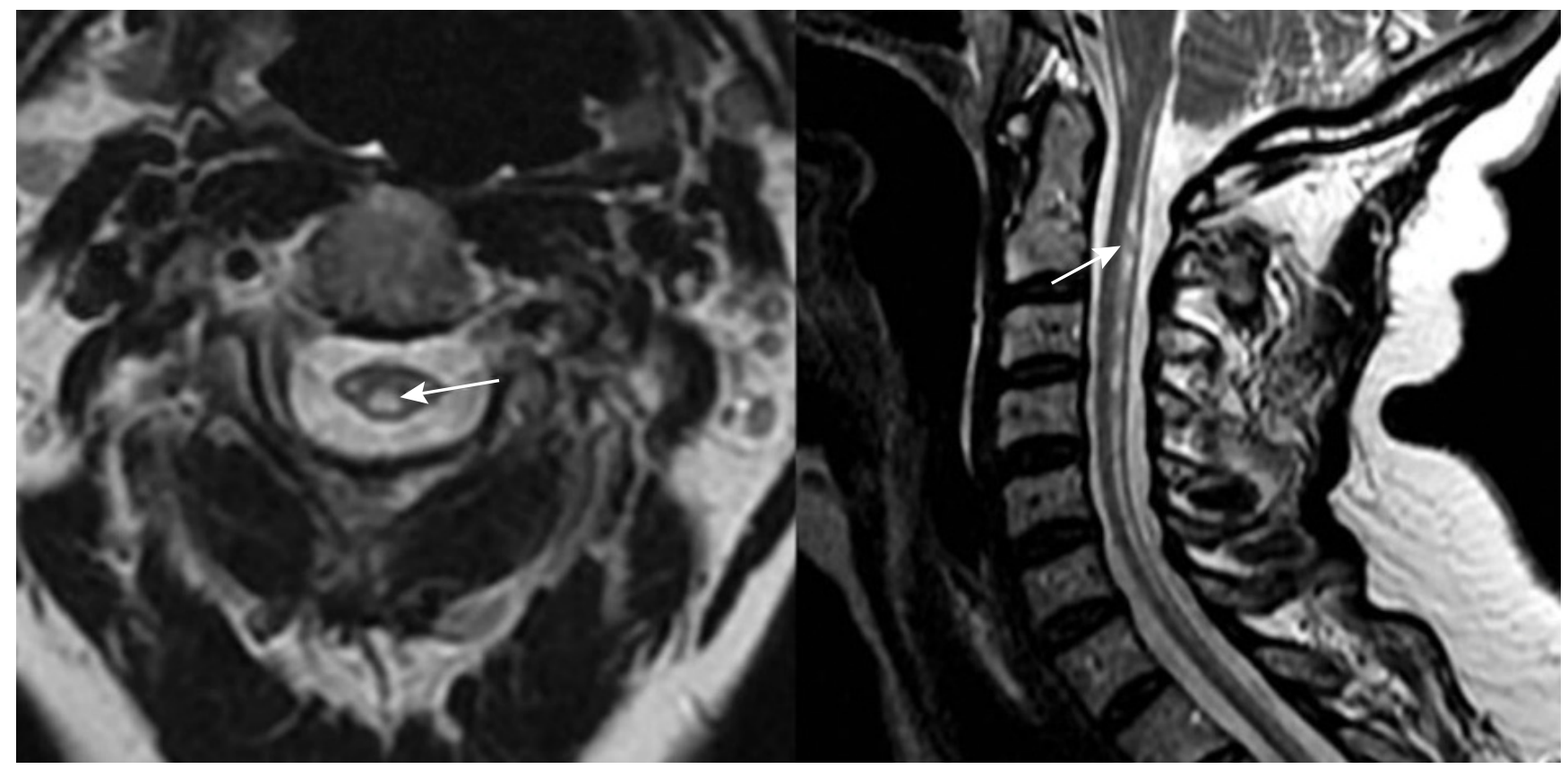

Dr. Victor Hugo Rocha Marussi (Medimagem, Beneficência Portuguesa de São Paulo).

Figure 3. Patient with acute sensory ataxia related to vitamin B12 deficiency. T2-weighted spine MRI shows hyperintense signal in the posterior column of the spinal cord.

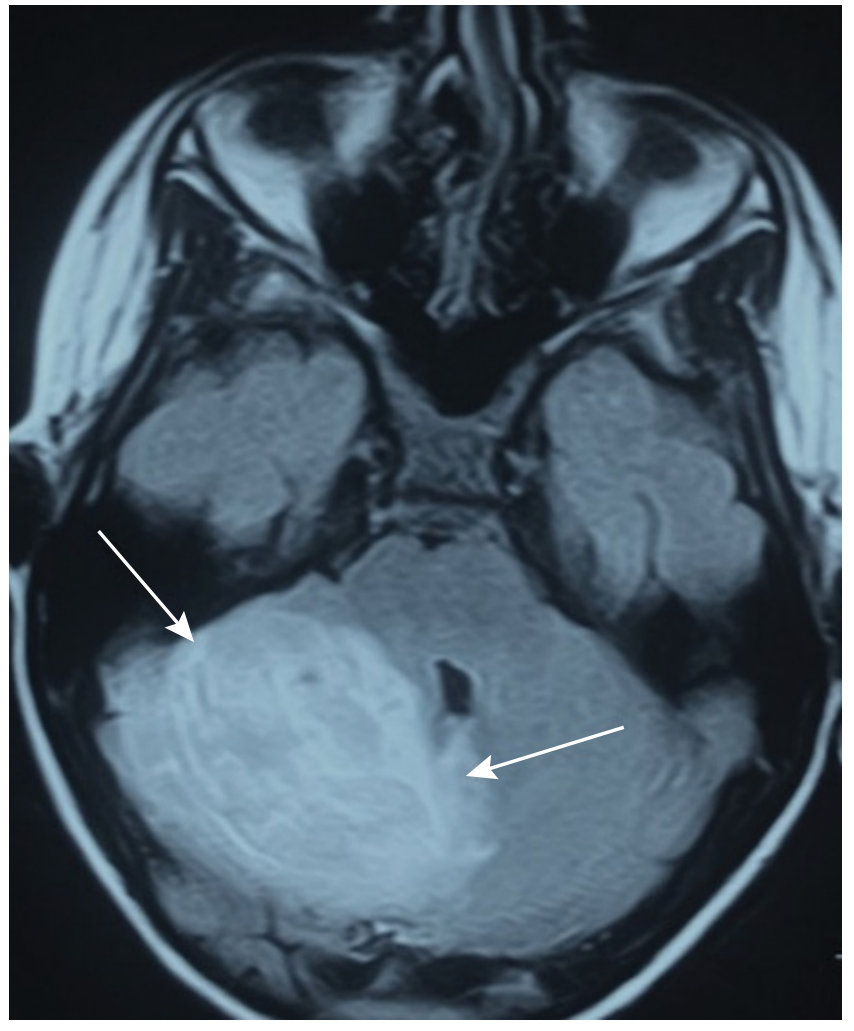

Figure 4. Patient with sudden ataxia. Axial FLAIR-weighted brain MRI disclosed acute ischemic stroke in the territory of the superior cerebellar artery, with compression of the fourth ventricle.

hydrocephalus from fourth ventricle outlet obstruction ${ }^{35}$. Other space-occupying lesions, such as cerebellar lesions, abscesses and arteriovenous malformations that undergo hemorrhagic transformation, may manifest with acute ataxia. Less common etiologies for space-occupying cerebellar lesions include giant multiple sclerosis plaques and tumefactive multiple sclerosis lesions, traumatic subdural hematoma, and progressive multifocal leukoencephalopathy. All patients found to have cerebellar space-occupying lesions, with the potential for caudal and rostral herniation of cerebellum, need immediate attention, as these can be life-threatening events ${ }^{3,35}$. Worrisome premonitory clinical manifestations of cerebellar herniation include ataxia, intractable headache, nausea and vomiting, photophobia, and decreased consciousness. As the pathologic process progresses, patients may evolve into stupor and then coma, along with an ataxic respiratory pattern. In Chiari malformation, caudal displacement of the cerebellar tonsils enter through the foramen magnum and clinical manifestation are diverse, depending on the severity: headache, ataxia, radicular limb pain, weakness, paresthesia, vestibular symptoms, diplopia, tinnitus, hearing loss, syncope, slurred speech, dysphagia, urinary incontinence and sleep disturbance ${ }^{36}$. Patients with Chiari hardly ever present with acute or subacute ataxia. Brain MRI is the gold standard method for diagnosis.

\section{METABOLIC AND GENETIC DISEASES ASSOCIATED WITH ACUTE CEREBELLAR ATAXIA}

Metabolic and genetic diseases associated with acute ataxias are more commonly observed in children, and hardly ever occur in adults. Biotinidase deficiency is an inherited disorder associated with the presence of seizures, hypotonia, respiratory 


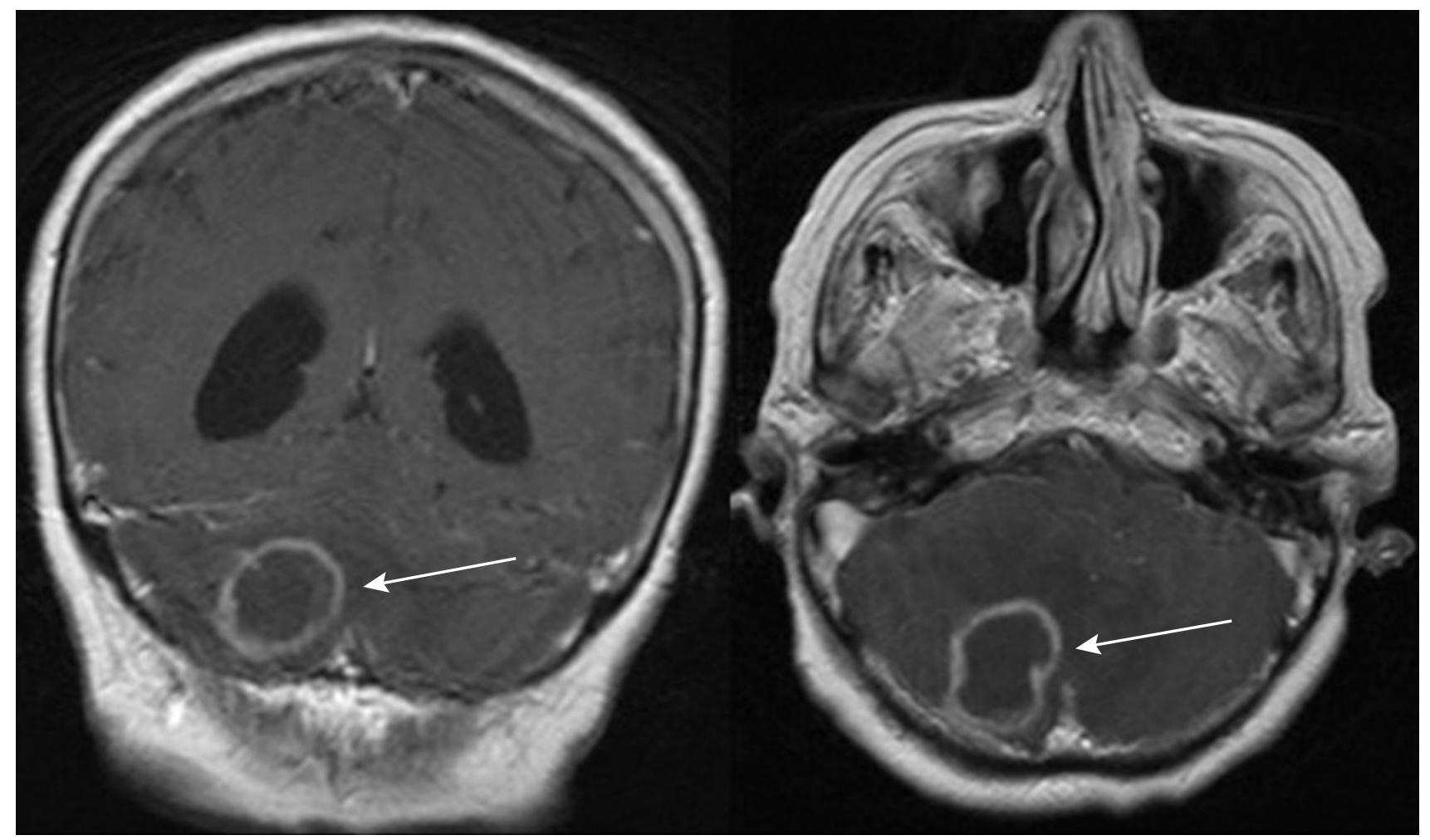

Figure 5: Kidney transplant recipient patient with acute ataxia. Brain MRI shows an expansive lesion with gadolinium enhancement in the cerebellum. Biopsy confirmed central nervous system post-transplant lymphoproliferative disorders.

problems, hearing loss and optic atrophy. Other clinical findings are skin rash, hair loss and conjunctivitis. Patients with late-onset biotinidase deficiency may present with ACA, especially after an acute stressor, such as prolonged infection ${ }^{37}$. Maple syrup urine disease is an autosomal recessive aminoacidopathy. The disease is named for the presence of sweet-smelling urine and affected patients frequently present with intermittent events of acute ataxia, drowsiness and seizures ${ }^{38}$. Treatment involves a protein-restricted diet and supplementation with essential amino acids and micronutrients. Hartnup disease is an autosomal recessive aminoaciduria characterized by abnormal gastrointestinal and renal transport of neutral amino acids. Patients may have light-sensitive dermatitis, emotional instability, psychotic symptoms, seizures and intermittent episodes of ataxia symptoms ${ }^{39}$. Mitochondrial disorders like pyruvate dehydrogenase deficiency, pyruvate decarboxylase deficiency and Leigh syndrome may have intermittent or acute episodes of cerebellar ataxia, frequently associated with lactic acidosis ${ }^{39}$. Episodic ataxias, particularly type 1 and type 2 , which are the most common forms, may cause recurrent symptoms of ACA. Family history and genetic features are crucial for the diagnosis ${ }^{40}$.

\section{OTHER CAUSES OF ACUTE CEREBELLAR ATAXIA}

\section{Childhood periodic syndromes}

Previously called "childhood periodic syndromes that are commonly precursors of migraine" in the International
Classification of Headache Disorders (ICHD)-II or colloquially "childhood periodic syndromes", these disorders were renamed "episodic syndromes that may be associated with migraine" in the ICHD-III beta. Infant colic affects young babies, benign paroxysmal torticollis older infants, benign paroxysmal vertigo typically affects preschool-aged children, abdominal migraine and cyclical vomiting affects schoolaged children around six or seven years of age ${ }^{41}$. An important feature of all these disorders is that, between attacks, the patients are healthy and have a normal neurologic examination. Acute episodes of ataxia can be an accompanying symptom of benign paroxysmal torticollis, which is characterized by periodic, stereotyped bouts of torticollis during infancy, typically beginning to improve by age two and resolving by age three or four. Drowsiness, irritability, apathy, pallor, vomiting or tortipelvis may also occur during the episodes. The etiology of benign paroxysmal torticollis is unknown. Some authors postulated it might be due to vestibular disorders or those in the central vestibular region or vestibulocerebellar connections, especially when associated with ataxia ${ }^{42,43}$. The hypothesis of channelopathy was also raised, and this entity was recently linked to mutation of the CACNAIA gene.

\section{Psychogenic ataxia}

Psychogenic movement disorders may present with a broad spectrum of phenomenology that may resemble, but can be differentiated from, organic movement disorders by careful history and examination, sometimes 
supplemented by ancillary tests ${ }^{44}$. Psychogenic gait disorders may have various clinical presentations, such as ataxia. The most frequent pattern is astasia-abasia, characterized by bizarre contortions and side-to-side swaying of their bodies, usually accompanied by buckling at the knees, maintaining good balance and even being able to perform the tandem gait. Patients may have spontaneous improvement, but recurrence or a chronic psychogenic gait disorder may also occur ${ }^{45}$.

\section{Migraine with brainstem aura and other vestibular disorders}

Migraine with brainstem aura, previously named basilar migraine or basilar-type migraine, is a subcategory of migraine with aura. Ataxia is listed among the brainstem symptoms that may occur during an attack, together with dysarthria, vertigo, tinnitus, hypoacusis, diplopia and decreased level of consciousness. A therapeutic response to a medication that prevents migraine headaches may assist to ratify the diagnosis of ACA secondary to basilar migraine ${ }^{46}$. Brain MRI is usually normal. Vestibular neuritis is characterized by an acute onset of sustained rotatory vertigo combined with horizontal rotatory peripheral vestibular spontaneous nystagmus toward the unaffected ear, which are typically suppressed by visual fixation. Examination reveals a pathological head-impulse test and postural imbalance. Ataxia may accompany the vestibular neuritis crisis, frequently associated with nausea and vomiting, without hearing loss and other neurologic abnormalities ${ }^{47}$. We must consider the differential diagnosis of a minor brainstem stroke when ataxia is an important feature.

\section{CONCLUSION}

In conclusion, ACA is a syndrome that evolves in less than 72 hours, affecting previously-healthy individuals. Acute cerebellar ataxia is commonly seen in neurological practice and patients are initially seen by clinicians at the emergency department. There is a wide array of causes of ACA, including vascular, neoplastic, nutritional, metabolic, immune-mediated, infectious, toxic and paraneoplastic. Acute cerebellar ataxia usually results in hospitalization and extensive laboratory investigation. Clinicians are often faced with deciding the extent and timing of initial screening tests, particularly to detect treatable causes.

\section{References}

1. Klockgether T. Sporadic ataxia with adult onset: classification and diagnostic criteria. Lancet Neurol. 2010 Jan;9(1):94-104. https://doi.org/10.1016/S1474-4422(09)70305-9

2. Barsottini OG, Albuquerque MV, Braga-Neto P, Pedroso JL. Adult onset sporadic ataxias: a diagnostic challenge. Arq Neuropsiquiatr. 2014 Mar;72(3):232-40. https://doi.org/10.1590/0004-282X20130242

3. Javalkar V, Kelley RE, Gonzalez-Toledo E, McGee J, Minagar A. Acute ataxias: differential diagnosis and treatment approach. Neurol Clin. 2014 Nov;32(4):881-91. https://doi.org/10.1016/j.ncl.2014.07.004

4. Caffarelli M, Kimia AA, Torres AR. Acute ataxia in children: a review of the differential diagnosis and evaluation in the emergency department. Pediatr Neurol. 2016 Dec;65:14-30. https://doi.org/10.1016/j.pediatrneurol.2016.08.025

5. Pruitt AA. Infections of the cerebellum. Neurol Clin. 2014 Nov;32(4):1117-31. https://doi.org/10.1016/j.ncl.2014.07.009

6. Desai J, Mitchell WG. Acute cerebellar ataxia, acute cerebellitis, and opsoclonus-myoclonus syndrome. J Child Neurol. 2012 Nov;27(11):1482-8. https://doi.org/10.1177/0883073812450318

7. Connolly AM, Dodson WE, Prensky AL, Rust RS. Course and outcome of acute cerebellar ataxia. Ann Neurol. 1994 Jun;35(6):673-9. https://doi.org/10.1002/ana.410350607

8. Nachbauer W, Eigentler A, Boesch S. Acquired ataxias: the clinical spectrum, diagnosis and management. J Neurol. 2015 May;262(5):1385-93. https://doi.org/10.1007/s00415-015-7685-8

9. Bhattacharyya S, Darby RR, Raibagkar P, Gonzalez Castro LN, Berkowitz AL. Antibiotic-associated encephalopathy. Neurology. 2016 Mar;86(10):963-71. https://doi.org/10.1212/WNL.0000000000002455

10. Falagas ME, Kasiakou SK. Toxicity of polymyxins: a systematic review of the evidence from old and recent studies. Crit Care. 2006 Feb;10(1):R27. https://doi.org/10.1186/cc3995
11. Manto M, Perrotta G. Toxic-induced cerebellar syndrome: from the fetal period to the elderly. Handb Clin Neurol. 2018;155:333-52. https://doi.org/10.1016/B978-0-444-64189-2.00022-6

12. Grommes C, Griffin C, Downes KA, Lerner AJ. Steroid-responsive encephalopathy associated with autoimmune thyroiditis presenting with diffusion MR imaging changes. AJNR Am J Neuroradiol. 2008 Sep;29(8):1550-1. https://doi.org/10.3174/ajnr.A1113

13. Zhou JY, Xu B, Lopes J, Blamoun J, Li L. Hashimoto encephalopathy: literature review. Acta Neurol Scand. 2017 Mar;135(3):285-90. https://doi.org/10.1111/ane.12618

14. Briani C, Samaroo D, Alaedini A. Celiac disease: from gluten to autoimmunity. Autoimmun Rev. 2008 Sep;7(8):644-50. https://doi.org/10.1016/j.autrev.2008.05.006

15. Bürk K, Farecki ML, Lamprecht G, Roth G, Decker P, Weller M, et al. Neurological symptoms in patients with biopsy proven celiac disease. Mov Disord. 2009 Dec;24(16):2358-62. https://doi.org/10.1002/mds.22821

16. Pedroso JL, Braga-Neto P, Dutra LA, Barsottini OG. Cerebellar ataxia associated to anti-glutamic acid decarboxylase autoantibody (anti-GAD): partial improvement with intravenous immunoglobulin therapy. Arq Neuropsiquiatr. 2011 Dec;69(6):993. https://doi.org/10.1590/S0004-282X2011000700030

17. Vale TC, Pedroso JL, Alquéres RA, Dutra LA, Barsottini OG. Spontaneous downbeat nystagmus as a clue for the diagnosis of ataxia associated with anti-GAD antibodies. J Neurol Sci. 2015 Dec;359(1-2):21-3. https://doi.org/10.1016/j.jns.2015.10.024

18. Ariño H, Gresa-Arribas N, Blanco Y, Martínez-Hernández E, Sabater L, Petit-Pedrol M, et al. Cerebellar ataxia and glutamic acid decarboxylase antibodies: immunologic profile and long-term effect of immunotherapy. JAMA Neurol. 2014 Aug;71(8):1009-16. https://doi.org/10.1001/jamaneurol.2014.1011 
19. Lopez-Chiriboga AS, Komorowski L, Kümpfel T, Probst C, Hinson SR, Pittock SJ, et al. Metabotropic glutamate receptor type 1 autoimmunity: clinical features and treatment outcomes. Neurology. 2016 Mar;86(11):1009-13. https://doi.org/10.1212/WNL.0000000000002476

20. Pedroso JL, Dutra LA, Espay AJ, Höftberger R, Barsottini OG. Video Neurolmages: head titubation in anti-mGluR1 autoantibodyassociated cerebellitis. Neurology. 2018 Apr;90(16):746-7. https://doi.org/10.1212/WNL.0000000000005338

21. Heidbreder A, Philipp K. Anti-IgLON 5 disease. Curr Treat Options Neurol. 2018;20(8):29. https://doi.org/10.1007/s11940-018-0515-4

22. Kuwabara S. [Pathophysiology of ataxia in Fisher syndrome]. Brain Nerve. 2016 Dec;68(12):1411-4. Japanese. https://doi.org/10.11477/mf.1416200610

23. Vernino S. Paraneoplastic cerebellar degeneration. Handb Clin Neurol. 2012;103:215-23. https://doi.org/10.1016/B978-0-444-51892-7.00013-9

24. Leypoldt F, Wandinger KP. Paraneoplastic neurological syndromes. Clin Exp Immunol. 2014 Mar;175(3):336-48. https://doi.org/10.1111/cei.12185

25. Meena JP, Seth R, Chakrabarty B, Gulati S, Agrawala S, Naranje P. Neuroblastoma presenting as opsoclonus-myoclonus: A series of six cases and review of literature. J Pediatr Neurosci. 2016 Oct-Dec;11(4):373-7. https://doi.org/10.4103/1817-1745.199462

26. Höftberger R, Rosenfeld MR, Dalmau J. Update on neurological paraneoplastic syndromes. Curr Opin Oncol. 2015 Nov;27(6):489-95. https://doi.org/10.1097/CCO.0000000000000222

27. Ducray F, Demarquay G, Graus F, Decullier E, Antoine JC, Giometto B, et al. Seronegative paraneoplastic cerebellar degeneration: the PNS Euronetwork experience. Eur J Neurol. 2014 May;21(5):731-5. https://doi.org/10.1111/ene.12368

28. Mitoma H, Hadjivassiliou M, Honnorat J. Guidelines for treatment of immune-mediated cerebellar ataxias. Cerebellum Ataxias. 2015 Nov;2(1):14. https://doi.org/10.1186/s40673-015-0034-y

29. Spinazzi M, Angelini C, Patrini C. Subacute sensory ataxia and optic neuropathy with thiamine deficiency. Nat Rev Neurol. 2010 May;6(5):288-93. https://doi.org/10.1038/nrneurol.2010.16

30. Martinez Estrada KM, Cadabal Rodriguez T, Miguens Blanco I, García Méndez L. [Neurological signs due to isolated vitamin B12 deficiency]. Semergen. 2013 Jul-Aug;39(5):e8-11. Spanish. https://doi.org/10.1016/j.semerg.2012.06.006

31. Harding AE, Muller DP, Thomas PK, Willison HJ. Spinocerebellar degeneration secondary to chronic intestinal malabsorption: a vitamin E deficiency syndrome. Ann Neurol. 1982 Nov;12(5):419-24. https://doi.org/10.1002/ana.410120503
32. Datar S, Rabinstein AA. Cerebellar infarction. Neurol Clin. 2014 Nov;32(4):979-91. https://doi.org/10.1016/j.ncl.2014.07.007

33. Neugebauer H, Witsch J, Zweckberger K, Jüttler E. Space-occupying cerebellar infarction: complications, treatment, and outcome. Neurosurg Focus. 2013 May;34(5):E8. https://doi.org/10.3171/2013.2.FOCUS12363

34. Datar S, Rabinstein AA. Cerebellar hemorrhage. Neurol Clin. 2014 Nov;32(4):993-1007. https://doi.org/10.1016/j.ncl.2014.07.006

35. Lyons MK, Kelly PJ. Posterior fossa ependymomas: report of 30 cases and review of the literature. Neurosurgery. 1991 May;28(5):659-64. https://doi.org/10.1227/00006123-199105000-00004

36. Wu YW, Chin CT, Chan KM, Barkovich AJ, Ferriero DM. Paediatric Chiari I malformations: do clinical and radiologic features correlate. Neurology. 1999;53(6):1271-6. https://doi.org/10.1212/WNL.53.6.1271

37. Rahman S, Standing S, Dalton RN, Pike MG. Late presentation of biotinidase deficiency with acute visual loss and gait disturbance. Dev Med Child Neurol. 1997 Dec;39(12):830-1. https://doi.org/10.1111/j.1469-8749.1997.tb07552.x

38. Sitta A, Ribas GS, Mescka CP, Barschak AG, Wajner M Vargas CR. Neurological damage in MSUD: the role of oxidative stress. Cell Mol Neurobiol. 2014 Mar;34(2):157-65. https://doi.org/10.1007/s10571-013-0002-0

39. Winchester S, Singh PK, Mikati MA. Ataxia. Handb Clin Neurol. 2013;112:1213-7.https://doi.org/10.1016/B978-0-444-52910-7.00043-X

40. Choi KD, Choi JH. Episodic ataxias: clinical and genetic features. J Mov Disord. 2016 Sep;9(3):129-35. https://doi.org/10.14802/jmd.16028PMID:27667184

41. Headache Classification Subcommittee of the International Headache Society. The International Classification of Headache Disorders, 3rd edition (beta version). Cephalalgia. 2013; 33(9):629808. https://doi.org/10.1177/0333102413485658

42. Hadjipanayis A, Efstathiou E, Neubauer D. Benign paroxysmal torticollis of infancy: an underdiagnosed condition. J Paediatr Child Health. 2015 Jul;51(7):674-8. https://doi.org/10.1111/jpc.12841

43. Fernández-Alvarez E, Perez-Dueñas B. Paroxysmal movement disorders and episodic ataxias. Handb Clin Neurol. 2013;112:847-52. https://doi.org/10.1016/B978-0-444-52910-7.00004-0

44. Thenganatt MA, Jankovic J. Psychogenic movement disorders. Neurol Clin. 2015 Feb;33(1):205-24. https://doi.org/10.1016/j.ncl.2014.09.013

45. Sudarsky L. Psychogenic gait disorders. Semin Neurol. 2006 Jul;26(3):351-6. https://doi.org/10.1055/s-2006-945523

46. Kaniecki RG. Basilar-type migraine. Curr Pain Headache Rep. 2009 Jun;13(3):217-20. https://doi.org/10.1007/s11916-009-0036-7

47. Bisdorff A, Von Brevern M, Lempert T, Newman-Toker DE. Classification of vestibular symptoms: towards an international classification of vestibular disorders. J Vestib Res. 2009;19(1-2):1-13. 